\title{
Assessing the attitude and behaviour regarding the disposal of expired or unused medicines. Case study: Bucharest, Romania
}

\author{
Gabriela Manea1, Ana-Maria Taloș ${ }^{* 1,2}$, Iuliana Vijulie ${ }^{1}$, Mihaela Preda ${ }^{1}$, \\ Alina Mareci', Roxana Cuculici' ${ }^{1}$, Octavian Cocoș ${ }^{1}$ \\ ${ }^{1}$ University of Bucharest, Romania \\ ${ }^{2}$ Romanian Young Academy, Romania
}

Given that expired or unused medicines can be dangerous to both public health and the environment, legislative regulations on their handling and management are set up worldwide. One of the most critical measurement is good consumer advice on the safe disposal of medicines. In this context, the purpose of the study was to assess the attitude of pharmaceuticals consumers in Bucharest towards their management and their disposal after the expiration date, as well as to review the policy of pharmaceutical institutions. The study results showed that but in $80 \%$ of the cases, consumers in Bucharest do not return expired drugs to pharmacies. Moreover, the population does not benefit from real information campaigns in this regard. The management of expired medicines is insufficiently regulated from a legal point of view, especially in terms of obligation, but also in regard to the sanctions applied to the entities that sell them, which has a severe impact on the current situation.

Key Words: expired or unused medicines, perception, disposing, Bucharest, Romania

Article Info: Received: April 3, 2019; Revised: October 24, 2019; Accepted: October 25, 2020; Online: November 30, 2020.

\footnotetext{
* Corresponding author

Address: Faculty of Geography, University of Bucharest, N. Bălcescu Av., no. 1, Department of Human and Economic Geography, Bucharest, 010041

Phone: 0040213143508 - 3844| Email: ana.talos@geo.unibuc.ro

(C)2020 Human Geographies; The authors

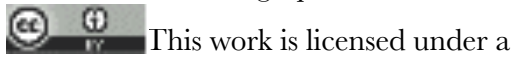

Creative Commons Attribution 4.0 International License. DOI:10.5719/hgeo.2020.142.4
} 


\section{Introduction}

Research conducted by the European Federation of Pharmaceutical Industries and Associations indicates that the pharmaceutical industry is one of the most booming industries both in Europe and in the rest of the world (EFPIA, 2018). In recent years, there is a demand, and implicitly a sharp increase in drug production. The European Union is the second market in this hierarchy, estimated at around 228.1 billion Euros for the sale of medicines, after the United States (24\% of world sales). Drug consumption in European countries varies from 50 to 150 grams/person/year (Zimmermann et al., 2018). Almost $80 \%$ of the world drug production is concentrated in the USA, Germany, the U.K., Switzerland, France, Japan, Italy, Canada, the Netherlands, Belgium and Denmark. In these countries, the pharmaceutical industry is severely controlled by the government, given that they are also in the top of large consumers (Univers Farmaceutic, 2012). Moreover, the pharmaceutical industries around the world have a significant contribution to improving the quality of the modern human's life, by providing the drugs needed to maintain good health. At the same time, it is essential that in the $21^{\text {st }}$ century, both manufacturers and drug users be aware of the importance of sustainable management of the waste deriving from the pharmaceutical industry. For this reason, an official protocol for the elimination and destruction of medicines by both consumers and approved bodies should be implemented worldwide (Tong et al., 2011; Paut Kusturica et al., 2017).

Pharmaceutical waste includes expired products, dispensed medicines that are unwanted or discontinued, as well as contaminated medications (Faisal, 2016; Kadam et al., 2016; Patil et al., 2016; Pratyusha et al., 2012; Xie \& Breen, 2012; Bungau et al., 2018). Likewise, pharmaceutical waste is not one single stream, but many distinct waste streams that can affect the integrity and uniformity of the chemicals present in pharmaceuticals products (Sreekanth et al., 2014). According to UNDP, there are 15 Pharmaceuticals and Personal Care Products (PPCP) that can make their way as pollutants in water and the environment, a fact that poses a severe issue of ecological imbalance due to the indiscriminate disposal of expired pharmaceutical products. At the same time, they may lead to the contamination of water supplies or local water sources used by nearby communities or wildlife. Most of the expired pharmaceuticals products are less effective and may develop adverse reactions (UNDP, 1999).

In this context, there are various legislative regulations worldwide on the handling and management of expired and unused medicines, given that they can be dangerous both for the health of the population and the environment.

Thus, the USA, the world's leading medicine manufacturer, pays special attention to the expired or unused drug circuit, which is divided into three levels. Firstly, there is a list of dangerous medicines, which must be collected in specialised centres, administered by the U.S. Drug Enforcement Administration (DEA) (FDA, 2020a). Then, there are two other categories of medicines that can be neutralised at home. A first category includes drugs that can be dissolved in water and disposed of in the toilet or sink. People have to check the label or the 
list of recommended medicines for disposal in the water on the U.S. Food and Drug Administration website (Remember, do not wash your medicine unless it is on the wash list!) (FDA, 2020a; FDA, 2020b). A second category includes medicines that can be disposed of in the trash under certain conditions. Thus, medicines are removed from their original containers and mixed, for example, with coffee grounds, dirt and cat litter.

As far as the disposal of expired medicines in Europe is concerned, an E.U. awareness-raising campaign on how to neutralise this category of waste has been carried out at E.U. Member State level. The aim of this campaign was to provide information on current schemes for the disposal of expired or unused medicines in European countries on the website http://medsdisposal.eu/ (MedsDisposal, 2020a). This is a joint initiative between European healthcare organisations, pharmaceutical industry and students, including several partners, as follows: Association of the European Self-Care Industry, The Council of European Dentists, The European Federation of Pharmaceutical Industries and Associations, The European Pharmaceutical Students' Association, EurEau.

At European level, the pharmaceutical market in Germany ranked first, with a turnover of almost 26 billion Euros. Germany has many regulations, at the state level, on the appropriate collection, management and neutralisation of expired or unused medicines. Therefore, this country provides its citizens with an online map, showing options for eliminating expired medicines for each federal state. In general, for the sustainable protection of the environment, groundwater and surface water, the disposal of medicines in the toilet or sink is not permitted (MedsDisposal, 2020b; Bundesministerium für Umwelt, 2020a). Despite the guidance offered in most European countries, in most German states, expired medicines can be thrown in the waste bin, with some exceptions (vaccines and medicines containing cytostatics, which are disposed of through municipal collection centres or pharmacies) (MedsDisposal, 2020b; Bundesministerium für Umwelt, 2020b; Bundesministerium für Umwelt, 2020c). This needs to be done, because household waste is no longer stored untreated in landfills, but is mechanically and biologically incinerated or pre-treated. So, through burning, the active or inactivated pharmaceutical ingredients are destroyed and can no longer affect the environment. In the case of mechanical-biological pretreatment, the destruction is not complete for all active ingredients. For this reason, many municipalities cooperate with pharmacies and collection centres specially designed to neutralise expired medicines. There are also special vehicles that collect expired medicines from mobile collection points. Some pharmacies offer the possibility to return medicines voluntarily (for example, in the federal state of Berlin) (Bundesministerium für Umwelt, 2020b).

In France, according to current legislation, expired or unused pharmaceuticals must be returned to community pharmacies (MedsDisposal, 2020c). The French government has set up Cyclamed, a foundation that collects expired drugs from the population through pharmacies (Cyclamed, 2018). According to it, in 2017, approximately 11 tons of expired drugs were collected, i.e. 164 grams per capita (Green Report, 2018). The French government's 
program can be considered an example of good practice, as the elimination of expired medicines is capitalised on in terms of energy. About 7,000 homes are lit and heated from this source.

Other examples of European countries where the delivery of expired medicines in pharmacies or, as the case may be, to family doctors, is mandatory are Italy, Portugal, and Hungary. (Green Report, 2018).

In the case of Ireland, the appropriate method of disposing of the expired medicines is also to return them to pharmacies. However, at present, there is an ad hoc system in this country, through which some pharmacies accept expired medicines for return, and others do not. The Irish Pharmaceutical Society advises its members to inform the public about the necessity to return the unused medicines to pharmacies so that they can be disposed of safely. However, pharmacies do not have to accept returns because the costs of disposal are borne entirely by them (Vellinga et al., 2014).

In Romania, the legislative framework on the use, handling, storage and destruction of medical waste is established by a series of laws and regulations that partially clarify the aspect of collecting expired or unused medicines. This task falls exclusively to pharmaceutical points, without becoming a mandatory condition in the process of authorising their operation. Thus, the Order of the Ministry of Health no. 119/2014, Chapter V, Article 38, regarding The hygiene norms regarding the collection, disposal and neutralisation of solid waste stipulates that expired medicines from the population will be collected in pharmacies, which have the task of neutralising them by incineration (Portal Legislativ, 2014). Both the Regulation of 29 July 2009 and that of 25 March 2019, on The establishment, organisation and operation of pharmacies and drugstores, refer to the obligation for each unit to have a special area dedicated to the storage of expired or collected medicines for destruction (Portal Legislativ, 2009; Portal Legislativ, 2019). The Romanian legislation, respectively Law no. 95/2006, updated on 6 April 2017, art. 872, as well as Law no. 339 of 29 November 2005, also refer to particular categories of pharmaceutical waste, respectively psychotropic and narcotic waste, with their recycling being the responsibility of pharmacies as well (Portal Legislativ, 2005; Portal Legislativ, 2006). The supervision of the previously stated norms is the responsibility of the National Agency for Medicines and Medical Devices of Romania, which can undertake controls in pharmacies, every five years or whenever needed (ANMDMR, 2019). It is important to observe that the management/destruction of expired medicines in Romania is insufficiently regulated from a legal point of view, in terms of obligation and sanctions.

The management of unsold expired medications is the responsibility of the polluter, respectively the manufacturer, who has to destroy them or cover the costs, while the management of expired drugs collected from the population falls exclusively on pharmacies, which must sign separate contracts with companies specialised in hazardous waste disposal (Univers Farmaceutic, 2017). The procedure followed by a consumer when handing over expired or unused medicines to a pharmacy is not a unitary one, the legislation providing strict rules exclusively in the case of the category of psychotropic and narcotic drugs. These 
medicines are accepted based on a report drawn up in triplicate (one for the pharmacist, one for the company that deals with their annihilation and one for the consumer). This report requests information about the consumer, the type and quantity of medicinal products delivered, information on the unit which accepts them, as well as the reason for the return. In the case of medicines falling into other categories, pharmacists apply the same bureaucratic procedure, which is considered difficult by customers, practically discouraging the return activity.

Given the Romanian context regarding expired or unused medicines, the purpose of the study was to assess the perception/attitude of the pharmaceuticals consumers in Bucharest towards their management and return/destruction after expiration, as well as to review the policies and practices of pharmaceutical units regarding their management.

\section{Methodology}

The authors' intention is to draw attention to pollution due to active substances contained in medicines disposed of incorrectly and to make consumers aware of the management of unused or expired drugs. The objectives of the study focused on the following aspects: highlighting the attitude of pharmaceutical consumers towards the management of expired or unused medicines; identification of the circuit of ex expired or unused medicines; analysing the available information sources on the management of unused and/or expired medicines.

The case study focuses on the city of Bucharest, which is the capital of Romania. This choice is justified, on the one hand, by the fact that Bucharest is the city with the largest number of inhabitants in the country and, on the other hand, it has the largest number of pharmaceutical units.

In order to achieve the stated objectives, the study employed the survey method, involving two stages. The first stage included applying a questionnaire among the users of pharmaceutical products, which was done in OctoberDecember 2019. Consequently, 322 consumers were asked about the frequently used medicines, the amount of medicines left unused or expired per a year, the pharmacies that they frequent the most, the proportion in which they returned expired or unused medicines, and the sources of information they accessed on the proper management of unused and/or expired medicines. The profile of the respondents can be seen in the table below (Table 1). People of different ages, with different educational backgrounds and different genders, were interviewed.

Table 1. Respondents' profile

\begin{tabular}{clclcl}
\hline Age & $\%$ & Educational status & $\%$ & Gender & $\%$ \\
\hline 18-35 years & 32.3 & Medium-level & 58.4 & Man & 40.4 \\
36-64 years & 50.9 & High-level & 41.3 & Women & 59.6 \\
over 65 years & 16.8 & N/A & 0.3 & & \\
\hline \multicolumn{2}{l}{ Source: Computed from the field survey } & &
\end{tabular}

Source: Computed from the field survey 
The second stage took place in January-March 2020 and consisted of the application of a semi-structured interview guide in pharmacies in Bucharest. The main objectives of these intervies were to identify the circuit of expired pharmaceutical products and to collect information on their management. Thus, 111 interviews were conducted in pharmacies; the information obtained referring to the type of medicines commonly bought, the stages involved in their destruction, the estimated amount of waste during a year, the presence of information on the management of expired or unused medicines inside the location and any awareness campaigns the pharmacies might have organised. The map showing the location of the pharmaceutical units that answered the applied questionnaire was made using the vector data for Bucharest City, scale 1:5000. These data were extracted from colour aerial images with $50 \mathrm{~cm}$ resolution, in a coordinate system Stereo 70 Romania. All extracted data were stored in a GIS database and were subsequently analysed in ArcGis Pro software (Figure 1).

As far as Bucharest is concerned, there are 516 pharmaceutical units arranged as follows: 103 pharmacies in Sector 1, 108 pharmacies in Sector 2, 85 pharmacies in Sector 3, 81 pharmacies in Sector 4, 43 pharmacies in Sector 5, and 96 pharmacies in Sector 6. The interview guides were applied in 111 pharmacies, selected in such a way as to be cover all sectors of the city. Consequently, interviews were conducted in 15 pharmacies in Sector 1, 15 pharmacies in Sector 2, 20 pharmacies in Sector 3, 24 pharmacies in Sector 4, 18 pharmacies in Sector 5 , and 19 pharmacies in Sector 6.

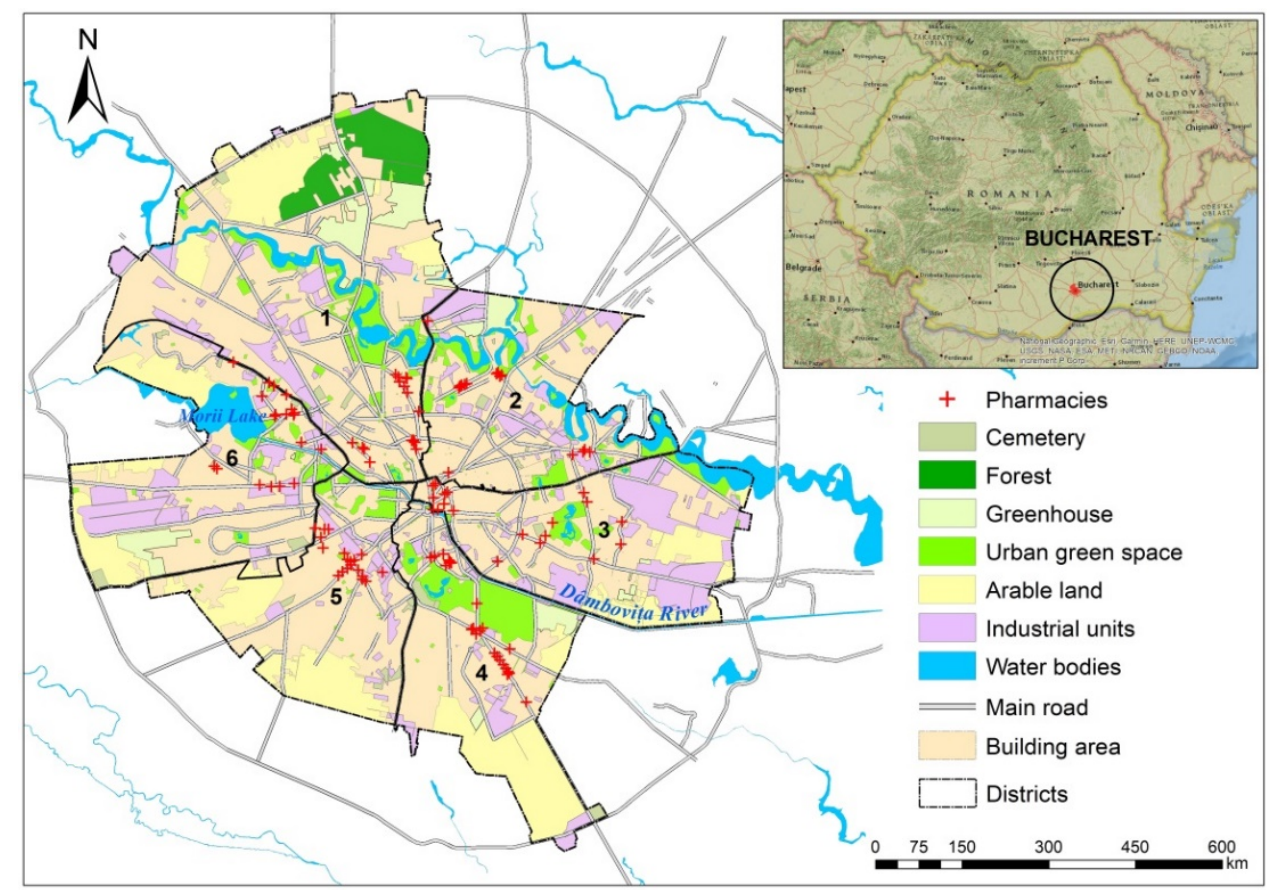

Figure 1. The distribution of Bucharest pharmacies in which the interview guide was applied 
The field data were processed in the SPSS program. Tests such as descriptive analysis and crosstab were employed. Descriptive analysis, which helps to describe a group of scores, is the simplest procedures of descriptive statistics, and it allows the understanding of the trend of a group of scores. The scores of the subjects are grouped in tables, thus making the information easier to observe and understand. Crosstabs in SPSS is just another name for contingency tables, which summarise the relationship between different variables of categorical data. They are useful to show the proportion of cases in subgroups.

In order to compare and confirm the information related to the manner in which the public is assisted about the proper disposal of unused or expired medicines, the authors also did an internet screening for all pharmacies in which interview guides were taken. The items analysed were the following: the inclusion of the pharmacy chain into a franchise or a larger conglomerate, the existence of an official website, the existence of a Facebook page, and most importantly a clear reference of the pharmacy's website or page to the correct disposal of unused or expired medication.

The statistical analysis on the perception of Bucharest consumers concerning the management and destruction of medicines after expiration, as well as the assessment of the attitude of employees in the pharmaceutical field related to this topic highlighted a series of results, related to each objective.

\section{Highlighting the attitude of pharmaceutical consumers towards the disposal of expired or unused medicines}

Expired and unused medicines fall into the category of hazardous waste, which should not go to landfills, but towards companies specialised in their disposal. As such, the people who buy those products must return them to pharmacies to be passed on to companies that specialise in neutralising them.

The survey found that adults were the most to return expired products, with about $66.7 \%$ of the respondents doing so, followed by only $33 \%$ of young people. We found it striking that none of the elders declared they returned expired or unused medicines to pharmacies. As for the level of education of those who return medicines, it was observed that those with a secondary education do it more $(66.7 \%)$ than those with higher education (33.3\%). Many respondents found it difficult to estimate the amount of pharmaceutical products left unused during a year $(50 \%$ of those with secondary education and $50 \%$ of those with higher education). However, the maximum declared amount was of more than 5 boxes per month was chosen mainly by those with secondary education $(82.4 \%)$ compared to $17.6 \%$ of those with higher education.

The methods used by the interviewees to dispose of them are diverse: they throw them in the toilet bowl or the trash, store them at home, return them to the pharmacy, or burn them. Irrespective of the age of consumers (18-35 years, 3664 years or over 65 years), their level of education (secondary or higher education) or their gender, expired medicines end up in the trash in more than 
$79 \%$ of the cases. The second way to get rid of the expired products is to throw them in the toilet. The analysis showed that those over the age of 65 , those with higher education and the male ones preferred this method. When having been left with 2-5 boxes of medicines unused during a year, $2.4 \%$, of products were returned to pharmacies and $87 \%$ being thrown in the trash. The situation is similar even if the amount of expired products is higher or lower.

According to the questionnaire applied to consumers, the medicines bought most frequently by respondents are those for colds and flu (37.2\%), followed by analgesics (17\%), anti-inflammatory (13.8\%) and medicines for digestive diseases $(8.4 \%)$. Pharmacists responded that cold and flu medications are the most requested $(37.5 \%)$, followed by specific medications $(13.2 \%)$, analgesics and antiinflammatory drugs (each with $8.8 \%$ ), thus confirming the general behaviour of the population related to medicine purchase.

\section{Identifying the circuit of expired pharmaceutical products}

During the field survey, in which 111 pharmacists were interviewed, $45.9 \%$ of the respondents said that the circuit of expired pharmaceuticals falls under the responsibility of specialised companies. The rest of $54.1 \%$ is represented by those who did not want to answer this question. Moreover, $78.4 \%$ of the pharmacists refused to disclose the name of the company specialised in the annihilation of pharmaceutical waste with which they concluded a contract (Table 2).

The most mentioned company was the Specialized Company no. 5, 10.8\% of the interviewees using its services, followed by the Specialized Company no. 2, nominated by $2.7 \%$ of the pharmacists. One can note that pharmacists indicate the municipal garbage collection company or courier companies that transport expired or unsold medicines to the supplier, as being responsible for the collection and destruction of pharmaceutical waste.

Table 2. Typology of companies responsible for taking over and destroying unused or expired medicines identified following the field survey

\begin{tabular}{lc}
\hline \multicolumn{1}{c}{ Typology of the company } & \% in the total no. of respondents \\
\hline Specialised company no. 1 & 0.9 \\
Municipal garbage collection company X & 0.9 \\
Specialised company no. 2 & 2.7 \\
Company with unknown name & 0.9 \\
Municipal garbage collection company Y & 0.9 \\
Specialised company no. 3 & 1.8 \\
Specialised company no. 4 & 0.9 \\
Courier company & 0.9 \\
Pharmacy & 0.9 \\
Specialised company no. 5 & 10.8 \\
N/A & 78.4 \\
\hline
\end{tabular}

Source: Computed from the field survey 
This aspect may indicate that pharmacies do not have a contract with a company specialised in the disposal of pharmaceutical waste, do not know the legislation or do not comply with its provisions. In some cases, the pharmacists stated that expired and unused medicines are destroyed by the pharmacy itself $(0.9 \%)$, although the law does not allow such a thing.

The field survey showed that $59.5 \%$ of the pharmacists preferred not to answer the question about the amount of pharmaceutical waste returned to the pharmacy in a year. The results of those who did answer are presented in Table 3.

Regarding the solutions offered by pharmacists for improving the management of expired products, the processing of the interviews showed that $36 \%$ of the respondents did not mention any solution at all. In a similar way, $28.8 \%$ of pharmacists, the existing strategies should remain, as they saw no need to improve them, while $22.5 \%$ of them consider that better customer information would be needed, but without specifying the potential strategies for this, which confirms the lack of interest in this subject. A limited percentage of pharmacists indicated that potential solutions would be the placement of return boxes in pharmacies, offering financial benefits to consumers who return expired drugs, thus transferring the responsibility to the Public Health Directorate (Table 4).

\section{Analysing the information level on the management of expired or unused medicines}

Information on the suitable disposal of unused or expired medicines can be done through multiple media: T.V., radio or online campaigns; visual aids such as billboards, posters, flyers, or brochures; or face to face by pharmacists.

Table 3. The estimated quantity of unused or expired medicines collected in pharmacies during a year

\begin{tabular}{cc}
\hline Quantity & \% in the total no. of respondents \\
\hline $10-20 \mathrm{~kg}$ & 7.2 \\
$20-50 \mathrm{~kg}$ & 10.8 \\
N/A & 59.5 \\
More than $50 \mathrm{~kg}$ & 9.9 \\
Less than $10 \mathrm{~kg}$ & 12.6 \\
\hline
\end{tabular}

Source: Computed from the field survey

Table 4. Pharmacists' opinion on unused or expired medication management strategies

Type of strategy

The current ones

According to the law

Storage in boxes in pharmacies

Disposal of all waste by collecting it from the population

Financial incentives for those who return expired drugs

N/A

Better information

DSP units specialised in recycling
$\%$ in the total no. of

respondents

28.8

4.5

3.6

2.7

0.9

36

22.5

0.9

Source: Computed from the field survey 
Because people (especially in urban areas) are often surrounded by billboards and other visual aids, they tend to actively ignore them. Their high density also makes it difficult for the population to focus on them long enough to absorb their message. Since one-third of the respondents admitted that they did not know if the pharmacies they frequented had any informative materials on this subject or not, means their effectiveness is questionable. There was no significant difference in their answers based on age or gender. In addition to these issues, the Romanian legislation does not mandate that pharmacies should have any informative tool regarding the proper disposal of unused or expired medicines.

Multiple studies have proven the central role that pharmacies have in shaping the health care behaviour of the population and especially in directing their medication usage (Goel et al., 1996; Stewart et al., 2008; You et al., 2011; Bell et al., 2016). In Romania, as in many other countries, pharmacists and pharmacy personnel are often seen and used as surrogate GPs because of their high density, especially in urban areas, and their accessibility and availability. As such, they can be or become the most effective method of disseminating information on this topic, as they are the first person the public encounters. Their behaviour is a decisive factor in shaping the attitude of the general population concerning the safe disposal of unused or expired medication. Namely, it is essential that when buying medicines, the public is informed about the possibility of returning any expired medicines to the same location from which they procured them.

This is also very convenient because by using the same location for the procurement and disposal of expired medicines, the public saves time and effort. In fact, the proper training and motivation of this segment of personnel could prove more efficient and cost-effective than the informative materials and/or panels displayed in the pharmacy itself. Our field study further supports this, because while only $15.3 \%$ of the pharmacists confirmed the existence of informative panels/posters in their place of work, $67.5 \%$ of them told us they usually inform the population about the possibility of returning unused or expired medicine. Considering that this study was conducted in the capital city of the country, an alarming finding is that $7.2 \%$ of the field interviews identified locations where both these information channels were missing: no informative materials were found, and the personnel did not usually advise the population on returning expired medicines.

Even though more than half of the interviewed pharmacists declared they actively inform the public on this matter, only $4 \%$ of respondents said they were told about the possibility and/or obligation of returning unused or expired medicines.

The interviews targeting pharmacists took place in 111 individual pharmacies, representing 23 different names in the business. In order to further assess the actions these pharmacies take, if any, and to inform the population about the correct disposal of unused or expired medicines, apart from the interviews, we also screened the internet for confirming and/or comparing the results obtained in the field. The items analysed were the following: the inclusion of the pharmacy chain into a franchise or a more massive conglomerate, the existence of an official 
website, the existence of a Facebook page, and most importantly a clear reference of the pharmacy's website or page about the correct disposal of unused or expired medication. Out of the 23 different pharmacies, 5 are part of a more massive pharmaceutical conglomerate, which would give them access to increased financial and promotional resources. More than half of these pharmacies have a website and Facebook page, while 8 are only found on Facebook. Having a Facebook page could be a handy tool as this is a medium consulted daily by a large percent of the population. However, this is a tricky tool to use if someone wants to keep a message up for a long time, as any new information put up will eventually become obsolete as it is scrolled over. That being said, our analysis concluded that none of these channels contained any information about the correct disposal of unused or expired medicines and/or about returning them to any pharmaceutical units available to the population, although one of them did have an important campaign that ended with gathering 7 tons of expired medicines.

\section{Discussions}

Economic agents, respectively pharmacies, in most cases, choose not to encourage the population to return unused or expired medicines, the reason being related to the costs of their destruction that pharmacies have to pay. The high percentage of pharmacists who did not declare the name of the specialised company or indicate other economic operators who do not specialise in the annihilation of pharmaceutical waste proves that these contracts do not exist, one reason being the high costs that need to be paid exclusively by the pharmaceutical unit. At the same time, the high number of those who refused to indicate either the circuit of expired products taken from consumers or the company contracted for their management shows us that institutions do not fully comply with the legislation, which is easier due to lack of control and sanctions by the competent authorities. Basically, for a pharmacy to get an operating permit, it does not have to prove the existence of a service contract with a company specialised in the destruction of medicines or to provide the proof of taking over a minimum stock. The mandatory condition refers to the existence within the unit of a special space dedicated to expired medicines. This situation leads to a poor collection of unused or expired pharmaceuticals from the population. Therefore, their circuit is replaced by a mechanism starting from the lacunar legislation that, as far as the pharmacy is concerned, allows for the possibility not to pay a company specialised in taking and annihilating pharmaceutical waste. Implicitly, this fact does not encourage the public's intention to return medicines.

According to Romanian legislation, drug users must hand over to pharmacies all products that have exceeded the expiration date. Unfortunately, the process of returning expired drugs to pharmacies often causes dissatisfaction, both to pharmacists and consumers. Our field research was supported by the following declarations gathered from respondents (either pharmacist or general 
population): Practically, it seems that there is no one to come and fine the pharmacies if they do not offer this service to customers. In addition, many people do not even know that medicines are recycled (woman, 50 years old). In the past, I used to throw medicines in the garbage, because I didn't know where to take them ... This time, because I had a bag full of them and a pretty big curiosity about this subject, I decided to take them to a pharmacy to be recycled correctly and safely (man, 35 years old). Theoretically, there is a law whereby pharmacies are obliged to accept expired drugs and to continue to have contracts with (drug) incineration companies, whose task is to destroy them under control (pharmacist, 40 years old).

Pharmacists have the potential to be at the forefront of this approach, being in a position to educate consumers on the safe disposal of expired drugs. The proper advice given to consumers on the safe disposal of medicines can make a significant difference in terms of public health and environmental quality. The knowledge of the method of drug elimination should be as important as that related to drug use (Kadam et al., 2016). The main arguments for correctly disposing of medicines would be that they contain chemicals with a high capacity to pollute the natural components (water, air, soil, vegetation and fauna). When it comes to information on the possibility of returning expired products in pharmacies, respondents replied that in the pharmacies they frequented there were no information panels about the importance of returning products (64\%) and that pharmacists did not inform them about this issue (96\% of the situations).

The considerable gap observed during the field surveys between pharmacists who declared they actively inform the public on the correct disposal of expired medicines and the respondents who said they were not told about the possibility and/or obligation of returning them to pharmacies is a cause of concern and proof that the general public is insufficiently informed about the safe disposal of unused or expired medicines. The problem of expired and/or unused medicines is a sensitive one because the population is only slightly aware of the risks of pollution with active substances, which are toxic to nature.

Therefore, the current situation can be improved if decision-makers would elaborate strategies aimed at running awareness campaigns about the importance of correctly disposing of expired and/or unused medicines, and if they would also come up with legislative regulations regarding the obligations of pharmacies to collect and neutralise these products.

\section{Conclusions}

The results of the research conducted in Bucharest represent a step forward in raising the awareness of the population about how medicines should be managed, so as not to harm the quality of the natural environment and human life. The authors draw attention to the lack of information and, in particular, to the mismanagement of expired medicines. The survey conducted in Bucharest on how unused or expired drugs should be managed, highlighted, on the one hand, the precariousness of health and environmental education of the population, and 
on the other hand, the low involvement of pharmacy staff in advising consumers on the risks of discharging medicines into the environment. According to the field survey, the behaviour of pharmaceutical consumers reveals that those with secondary education return unused or expired drugs to pharmacies in a higher proportion than those with higher education.

The applying of interview guides addressed to pharmacists highlighted a dramatic phenomenon, with a negative impact on the quality of life, due to a lacunar legislation, but also to the lack of social responsibility on the part of the specialists regarding the problems generated by pollution with pharmaceutical waste. The low collection of unused or expired medicines is explained by the lack of obligation to conclude a contract with a company specialised in their destruction.

The promotion of the proper management of unused or expired medicines through various means of information should be intensified, so that the collective perception of human communities about the risks of contamination should reach the moment of transition from intention to action. In conclusion, we find that the circuit of expired pharmaceutical products is a step dependent directly on the legal regulations adopted by each state, under the rules of protecting the public health and the environment.

\section{Acknowledgement}

The article has benefitted from the support of the Romanian Young Academy, which is funded by Stiftung Mercator and the Alexander von Humboldt Foundation for the period 2020-2022.

\section{References}

ANMDMR - Agenția Națională a Medicamentului și a Dispozitivelor Medicale din România, (2019), Ordin Nr. 1.522 din 9 octombrie 2019 pentru aprobarea Regulamentului de organizare și funcționare al Agenției Naționale a Medicamentului și a Dispozitivelor Medicale din România. Publicat în Monitorul Oficial nr. 841 bis din 16 octombrie 2019, 24 September 2020, shorturl.at/ltDGL.

Bundesministerium für Umwelt, Naturschutz und nukleare Sicherhei (2020a), Arzneimittel-Entsorgung richtig gemacht!, 4 October 2020, shorturl.at/huIO9.

Bundesministerium für Umwelt, Naturschutz und nukleare Sicherhei (2020b), Arzneimittelentsorgung richtig gemacht!, 4 October 2020, shorturl.at/kGPQ2.

Bundesministerium für Umwelt, Naturschutz und nukleare Sicherhei (2020c), Arzneimittel-Entsorgung richtig gemacht!, 4 October 2020, shorturl.at/wBSY4.

BIO Intelligence Service (2013), Study on the environmental risks of medicinal products, Final Report prepared for Executive Agency for Health and Consumers, 10 October 2020, shorturl.at/imrEG. 
Bell, J., Dziekan, G., Pollack, C. and Mahachai, V. (2016), "Self-Care in the Twenty First Century: A Vital Role for the Pharmacist", Advances in Therapy, vol. 33 no. 10, p. 1691-1703.

Bungau, S., Tit, D.M., Fodor, K., Cioca, G., Agop, M., Iovan, C., Cseppento, D.C.N., Bumbu, A. and Bustea, C. (2018) "Aspects Regarding the Pharmaceutical Waste Management in Romania", Sustainability, vol. 10, p. 2788. Cyclamed (2018), Tous ensemble pour trier et rapporter les Médicaments Non Utilisés (M.N.U.) en pharmacie!, 10 October 2020, https://www.cyclamed.org/cyclamed/.

MedsDisposal (2020a), Disposal of medicines in Europe, 4 October 2020, http://medsdisposal.eu/.

MedsDisposal (2020b), Disposal of medicines in Germany, 4 October 2020, http://medsdisposal.eu/\#germany.

MedsDisposal (2020c), Disposal of medicines in France, 4 October 2020, http://medsdisposal.eu/\#france.

EFPIA - European Federation of Pharmaceutical Industries and Associations (2018) The pharmaceutical industry: a key asset to the European economy, 4 October 2020, shorturl.at/ckyJ2.

Faisal, (2016), "Research Analysis on Barriers to Green Supply Chain Management in Pharmaceutical Industries", Review of Public Administration and Management, vol. 3, no. 1, p. 176-180.

FDA (2020a), Where and How to Dispose of Unused Medicines, 2 October 2020, shorturl.at/yBRTZ.

FDA (2020b), Drug Disposal: FDA's Flush List for Certain Medicines, 2 October 2020, shorturl.at/ewHZ8.

Goel, P., Ross-Degnan, D., Berman, P. and Soumerai, S. (1996), "Retail pharmacies in developing countries: A behavior and intervention framework", Social Science E Medicine, vol. 42, no. 8, p. 1155-1161.

Green Facts (2020), The risks of environmental effects of pharmaceutical and medicinal products, 9 October 2020, shorturl.at/dgjnt.

Green Report (2018), Locul medicamentelor expirate nu e la coșul de gunoi, 10 October 2020, shorturl.at/yBK69.

Harvard Health Publishing (2020), Which painkiller is safest for you?, 10 October 2020, shorturl.at/cdoCG.

Kadam, A., Patil, S., Patil, S. and Tumkur, A. (2016), "Pharmaceutical Waste Management an Overview", Indian Journal of Pharmacy Practice, vol. 9, no. 1, p. 2-8.

Patil, P.S., Kumbhoje, S.R. and Patil, S.S. (2016), "Pharmaceutical Waste Management-An Overview", Asian Journal of Pharmaceutical Research, vol. 5, no. 2, p. 1-8.

Paut Kusturica, M., Tomas, A. and Sabo, A. (2017), "Disposal of Unused Drugs: Knowledge and Behavior Among People Around the World", Reviews of Environmental Contamination and Toxicology, vol. 240, p. 71-104.

Portal legislativ (2005), "Legea nr. 339 din 29 noiembrie 2005 privind regimul juridic al plantelor, substanțelor și preparatelor stupefiante și psihotrope", Monitorul Oficial nr. 1095 din 5 decembrie 2005, 24 September 2020, shorturl.at/ekKU3. 
Portal legislativ (2006), "Legea nr. 25 din 14 aprilie 2006 (republicată) privind reforma în domeniul sănătătii", Monitorul Oficial nr. 652 din 28 august 2015, 24 September 2020, shorturl.at/ntMS6.

Portal legislativ (2009), "Norme din 29 iulie 2009 (actualizate) privind înființarea, organizarea și funcționarea farmaciilor și drogheriilor (actualizate până la data de 22 aprilie 2010)", Publicat în Monitorul Oficial nr. 538 din 23 august 2009, 24 September 2020, shorturl.at/kBHRW.

Portal legislativ (2014), "Ordin nr. 119 din 4 februarie 2014 pentru aprobarea normelor de igienă și sănătate publică privind modul de viață al populației", Monitorul Oficial nr. 127 din 21 februarie 2014, 24 September 2020, shorturl.at/fiFNU.

Portal legislativ (2019), "Norme din 25 martie 2019 privind înființarea, organizarea și funcționarea unităților farmaceutice", Monitorul Oficial nr. 270 bis din 9 aprilie 2019, 24 September 2020, shorturl.at/xEITV.

Pratyusha, K., Gaikwad, N.M., Phatak, A.A. and Chaudhari, P.D. (2012), Waste material management in pharmaceutical industry, International Journal of Pharmaceutical Sciences Review and Research, 16(2), 121-129.

Sreekanth, K., Gupta, N.V., Raghunandan, H.V. and Kashyap, U.N. (2014), "A Review on Managing of Pharmaceutical Waste in Industry", International Journal of PharmTech Research, vol. 6, no. 3, p. 899-907.

Stewart, D.C., George, J., Bond, C.M., Cunningham, I.T.S., Diack, H.L. and McCaig, D.J. (2008), "Exploring patients' perspectives of pharmacist supplementary prescribing in Scotland", Pharmacy World E Science, vol. 30, no. 6, p. 892-897.

Tong, A.Y., Peake, B.M. and Braund, R., 2011. Disposal practices for unused medications around the world, Environment International, 37 (1):292-8.

UNDP - United Nations Development Programme (1999), Emergency Relief Items - Compendium of Basic Specifications, vol. 2, 10 October 2020, shorturl.at/btvG6.

Univers Farmaceutic (2012), Scurtă istorie a medicamentului, 8 October 2020, shorturl.at/nHKRX.

Univers Farmaceutic (2017), Gestionarea deșeurilor în farmacia comunitară, 29 September 2020, shorturl.at/nDJQ5.

Vellinga, A., Cormican, S., Driscoll, J., Furey, M., Sullivan, M. and Cormican, M. (2014), "Public practice regarding disposal of unused medicines in Ireland", Science of the Total Environment, vol. 478, p. 98-102.

Xie, Y. and Breen, L. (2012), "Greening community pharmaceutical supply chain in U.K.: a cross boundary approach", Supply Chain Management, vol. 17 no. 1, p. 40-53.

You, J.H., Wong, F.Y., Chan, F.W., Wong, E.L. and Yeoh, E. (2011), "Public perception on the role of community pharmacists in self-medication and selfcare in Hong Kong", BMC Clinical Pharmacology, vol. 11, no. 19.

Zimmermann, A., Rogowska, J. and Wolska, L. (2018), "Pharmaceutical household waste - role of community pharmacies", Farmacja polska, vol. 74, no. 1, p. $40-44$. 